
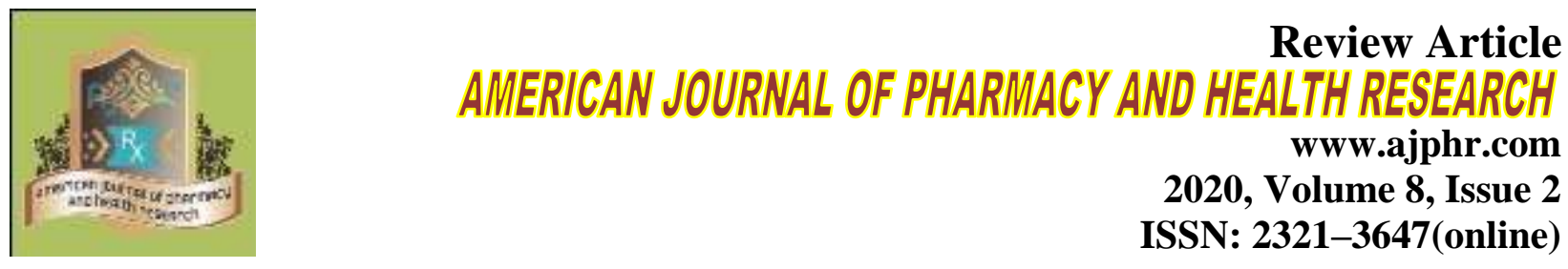

\title{
A Review On Proniosomes: Formulation, Characterization and Applications
}

\author{
Sunitha Reddy M*, Sheethal Lakum \\ Department of Pharmaceutics, Center for Pharmaceutical Sciences, IST, JNTU-H, Kukatpally, \\ 500085, Hyderabad, India.
}

\begin{abstract}
Nanotechnology is the advancing technology which is based on the study of manipulating the matter on a Nano scale range, and it refers to the constructing and engineering of the functional systems at atomic level. Nanotechnology lead to the development of various types of novel drug delivery systems like liposomes, microparticles, niosomes and proniosomes. Liposomes and niosomes has some demerits like leaking, fusion, aggregation, distribution, transportation and storage. To overcome the demerits of both liposomes and niosomes, proniosomes are developed with enhanced physical stability during storage and transport as they are dry formulation of water soluble carrier encoated with the surfactant and drug encapsulated in the proniosomal vesicles, which helps in prolongation of duration of retention of drug in systemic circulation and by reaching the target tissue shows its action which results in reduced toxicity. This review mainly focusses on demerits of liposomes and niosomes, methods of preparation, characterization and applications of Proniosomes.
\end{abstract}

Keywords: Liposomes, Niosomes, Proniosomes, Stability, Surfactant, Cholesterol, Characterization, Applications. 


\section{INTRODUCTION}

In the field of pharmaceutical sciences, great efforts are being conducted for the research and development of the various novel drug delivery system with the aim to achieve targeted and controlled drug delivery with reduced or minimal side effects when compared to the conventional system. Drug encapsulaltion in any of the vesicular system should prolong the duration of drug in the systemic circulation leading to enhanced therapeutic efficacy and bioavailability.

\section{Vesicular forms:}

Liposomes- These are developed as a colloidal, vesicular structures with concentric phospholipid bilayers. It contains an aqueous core inside to encapsulate the hydrophillic drug and due to the presence of phospholipid bilayer, lipophilic drug can be entrapped[1]. It can encapsulate both hydrophilic and lipophillic drugs.

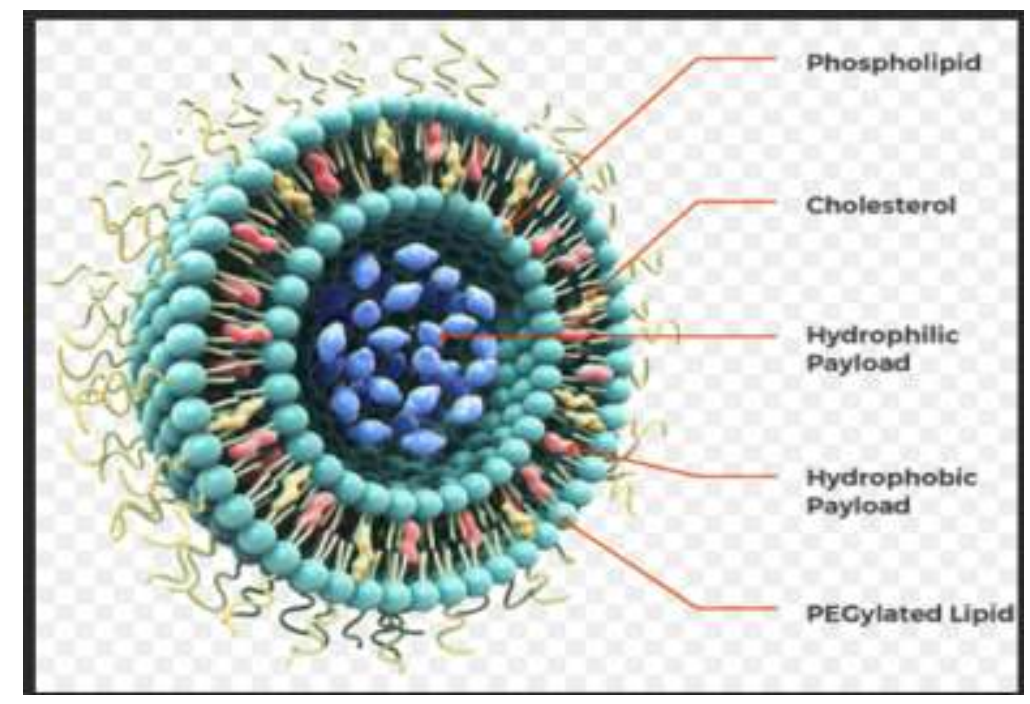

Figure 1: Structure of Liposomes

\section{Demerits -}

- When given by oral route, limited success is seen.

- Physicochemical stability problems (sedimentation, aggregation, fusion).

- Difficulty in sterilization and high cost.

- Hydrolysis/oxidation of phospholipids. (i.e., phospholipid purity)[2].

To overcome the stability problems of liposomes, proliposomal approach has been provided.

Proniosomes - Dry, free-flowing powdered formulations containing hydrophilic carrier particles which are coated with the phospholipids. On addition of water, it produces multi-lamellar liposomal suspension [3].

\section{Demerit -}


Technical difficulties such as usage of vacuum (or) nitrogen gas during preparation and storage for the prevention of oxidation of phospholipids [4, 5].

To overcome the limitations of the proliposomes and liposomes, niosomes are developed as drug carriers and drug targeting agents $[6,7]$.

\section{Niosomes}

These non-ionic surfactant vesicles which are capable of entrapping (or) encapsulating both hydrophilic and lipophilic drug as similar to that of liposomes.

- They are less toxic due to their non-ionic nature.

- The large-scale production of niosomes does not require any special conditions $[8,9]$.

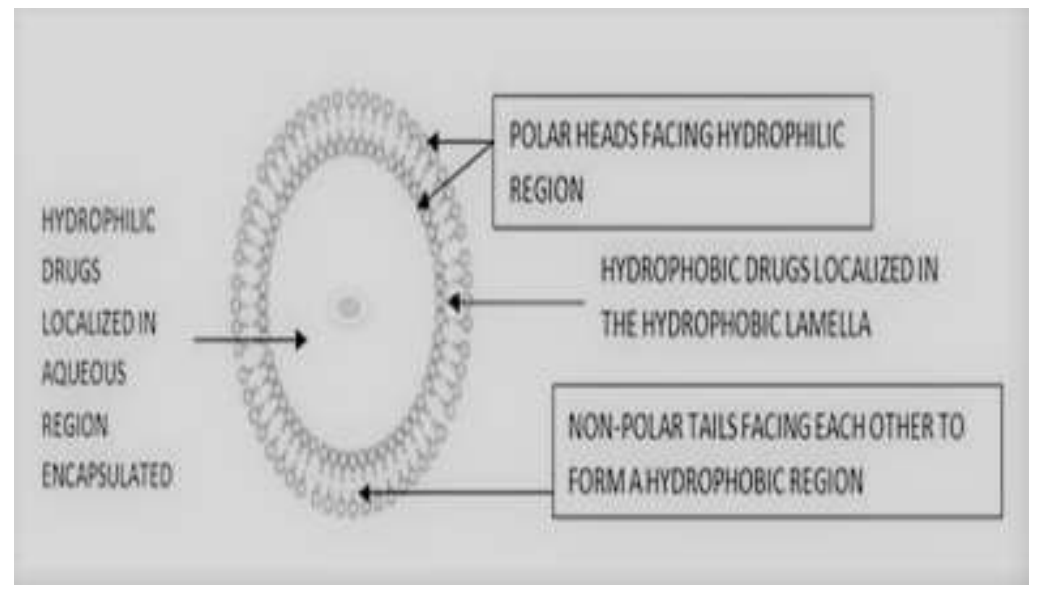

Figure 2: Structure of Niosomes

\section{Comparison between niosomes and liposomes:}

- Niosomes are less expensive than liposomes.

- Niosomes does not require any special conditions or methods for storage and handling of the formulation when compared to liposomes $[10,11]$.

- Niosomes contain non-ionic surfactants, where as liposomes contain phospholipids which are neutral or charged.

\section{Demerits -}

- $\quad$ Aggregation.

- $\quad$ Physical instability.

- $\quad$ Leaking of entrapped drug on storage.

- $\quad$ Time consuming for traditional method of preparation.

- $\quad$ Involves specialized equipment.

- Hydrolysis of encapsulated drugs which reduces the shelf life of the niosomal suspension[12]. 
To overcome the demerits of niosomes, proniosomes are prepared and reconstituted to produce niosomes.

\section{PRONIOSOMES}

Proniosomes are dry free-flowing formulations of surfactant-coated carrier, which on rehydration by agitation in hot water, produces a multi-lamellar niosomal suspension suitable for administration[13, 14].

Since these proniosomes are available in dry form of powders, they have a benefit in transportation, distribution, processing, packaging and storage. It can provide optimal flexibility, metered unit dosing in capsule and stability [15]. These versatile drug delivery system has the potential to be used as the carriers for many of the active pharmaceutical components [13, 16].

It minimizes the demerits of the niosomes in stability issues as these proniosomes are more stable when compared to pre-niosomal formulations.

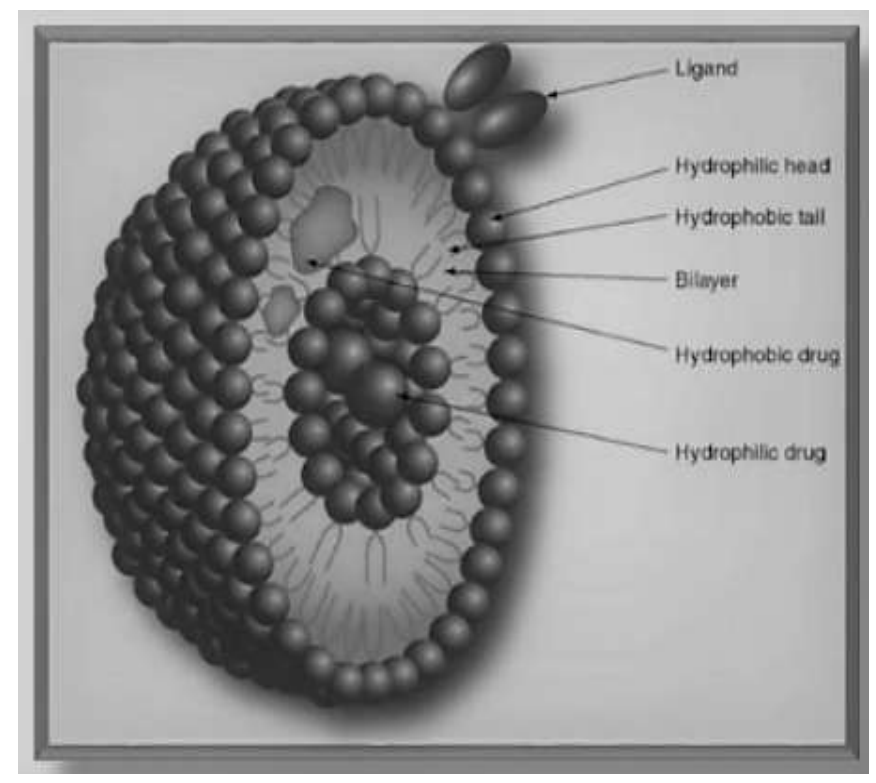

Figure 3: Structure of Proniosomes 


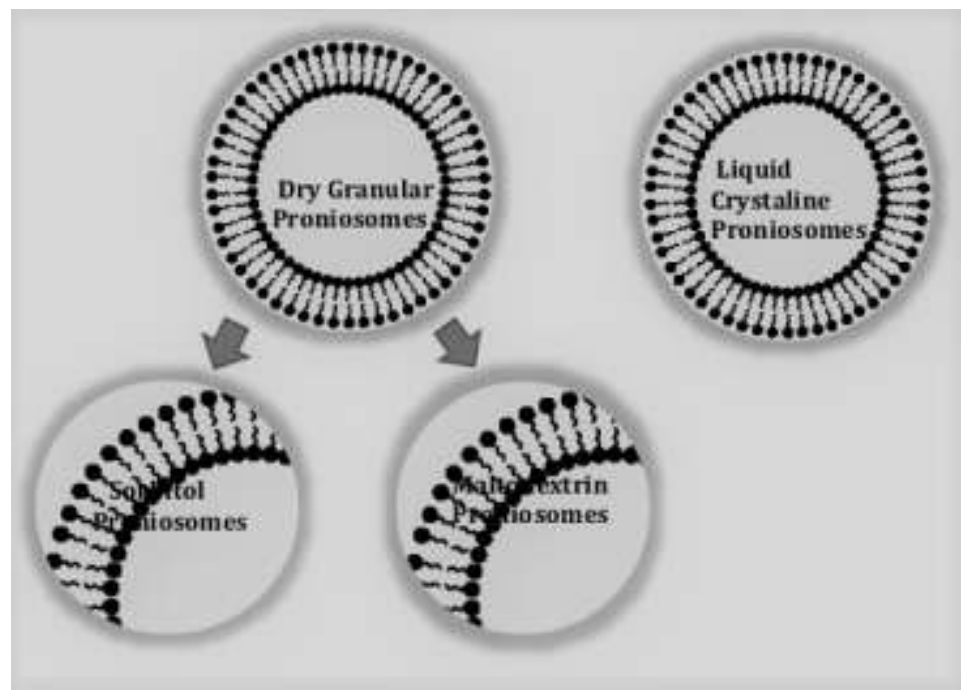

Figure 4: Types of Proniosomes

\section{Comparison of proniosomes with niosomes-}

- Niosomes are microscopic lamellar vesicles formed by the mixture of non-ionic surfactants and cholesterol in the aqueous media, where as the proniosomes are dry formulations of surfactant coated carrier vesicles which are capable to get hydrated to produce niosomes immediately before use.

- Niosomes can be degraded by hydrolysis while proniosomes are dry formulation and can not be degraded by hydrolysis.

- Use of unacceptable solvents in the preparation of niosomes.

- Incomplete hydration of lipid or surfactant film during hydration process for niosomal formulations[17].

\section{Ideal properties for the drug in proniosomal formulations -}

- Low aqueous solubility of drugs.

- High dosage frequency of drugs.

- Short half life.

- Controlled drug delivery suitable drugs.

- Higher adverse effects of drugs [18].

\section{Composition of proniosomes}

- Phosphotidyl choline - eg. Soya/egg lecithin.

- Drug.

- Non-ionic surfactants

i) Fatty alcohol - cetyl alcohol, stearyl alcohol, cetostearyl alcohol, oleylalcohol.

ii) Ethers- decyl glucoside, lauryl glucoside, octyl glucoside, triton X-100. 
iii) Esters- glyceryl laureate, polysorbates, spans.

- Solvents - eg. Ethanol, butanol, iso-propanol.

- Cholesterol

- Aqueous phase - eg. Water, glycerol, phosphate buffer [18].

\section{METHODS OF PREPARATION}

\section{Slurry Method -}

Firstly stock solution of surfactants and cholesterol was prepared by using a suitable solvent. The required volume of above prepared stock solution per gram of carrier and drug should be dissolved in the solvent in the 100ml RBF containing the carrier (i.e. maltodextrin/lecithin). Then add the chloroform which results in the formation of the slurry. This RBF was attached to a rotary flash evaporator to evaporate the solvent at 50-60 rotations per minute, at the temperature of $45 \pm 2{ }^{\circ} \mathrm{C}$ and at a pressure of $600 \mathrm{~mm} \mathrm{Hg}$, till the content present in the flask is dried and free flowing. Finally, the niosomal formulation should be stored at $4{ }^{\circ} \mathrm{C}$ temperature (i.e., refrigeration temperature) in a tightly closed container[12].

\section{Spray coating Method -}

Required amount of carrier has to be taken in a 100ml of RBF. Then surfactant and cholesterol mixture was prepared and this mixture was sprayed on to the carrier in RBF which is connected to the evaporator. By sequential spraying of the surfactant and cholesterol mixture on to the carrier until the aliquot coats the carrier and by the evaporation of the solvent, it becomes dry and free flowing powder, which was stored in a tightly closed container at $4^{\circ} \mathrm{C}[19]$.

\section{Co acervation phase separation method -}

This method is used for the preparation of proniosomal gel.

Desired amount of surfactant, carrier, cholesterol and drug should be weighed and taken in a clean wide mouthed glass vial. Then the solvent is added to the above mixture. All the ingredients in the mixture has to be heated and then after mixed with the help of the glass rod. To avoid the loss of solvent, the vial is closed at the open end with the help of the lid. This mixture is warmed on the water bath at the temperature of $60-70^{\circ} \mathrm{C}$ for $5 \mathrm{~min}$ until the surfactant dissolves completely and then it is allowed to cool down at a room temperature until the dispersion is converted to proniosomal gel[20]. 


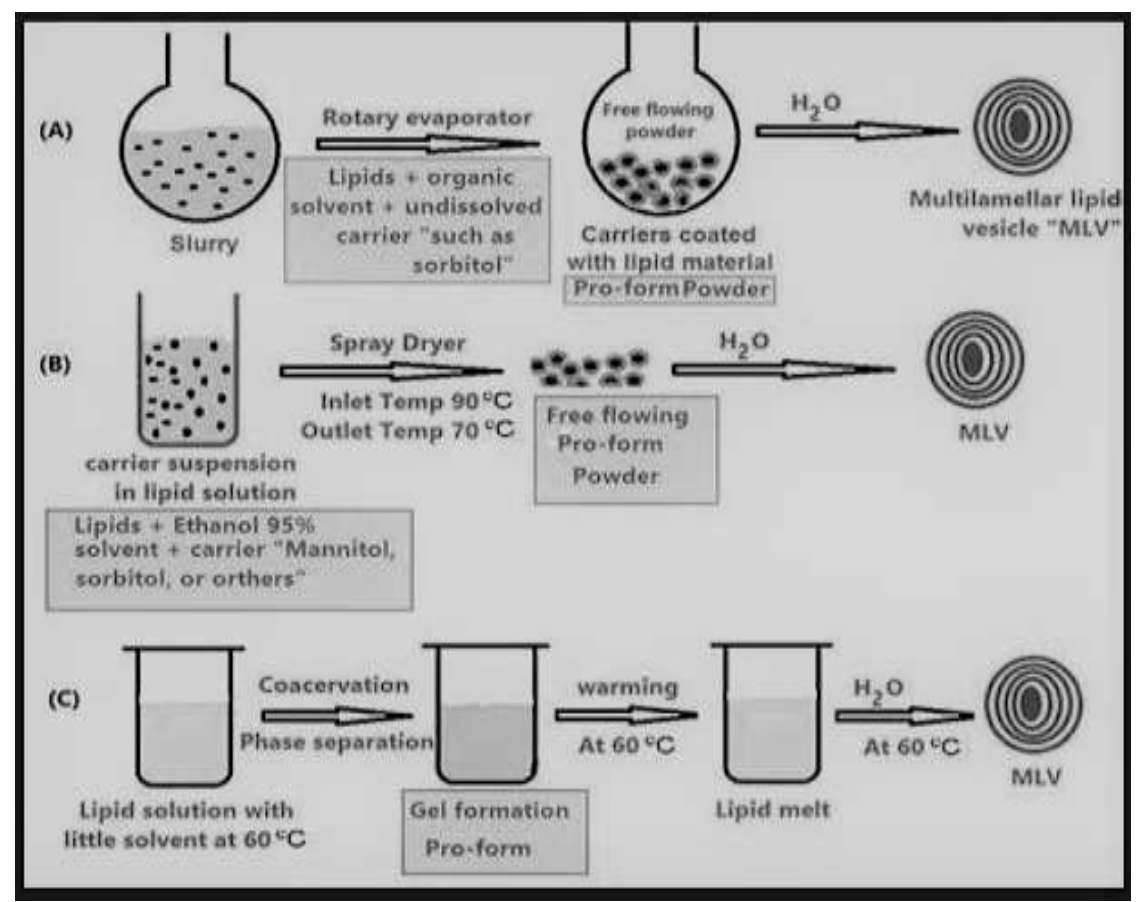

Figure 5: Different methods of proniosomal preparations
A. Slurry Method
B. Spray Coating Method
C. Coacervation Phase Separation Method

\section{Hand shaking method -}

Required amount of vesicle forming ingredients such as cholesterol and surfactants are dissolved in the suitable solvent (i.e. either ether, methanol or chloroform) in a RBF which is placed in a rotary evaporator. The organic solvent evaporates at a room temperature (i.e. $20-25^{\circ} \mathrm{C}$ ) leaving a thin film which is deposited on the walls of the container. On rehydration with the aqueous phase with little agitation, results in the formation of multilamellar niosomes[15].

\section{Conversion of proniosomes to niosomes-}

On addition of surfactant to the carrier surface, it forms a dry surfactant film on carrier surface which is able to enclose water soluble particles. On further addition of the water or the hydration of the proniosomes leads to the formation of niosomal vesicle which is capable of entrapping hydrophilic and hydrophobic drug particles (Fig). 


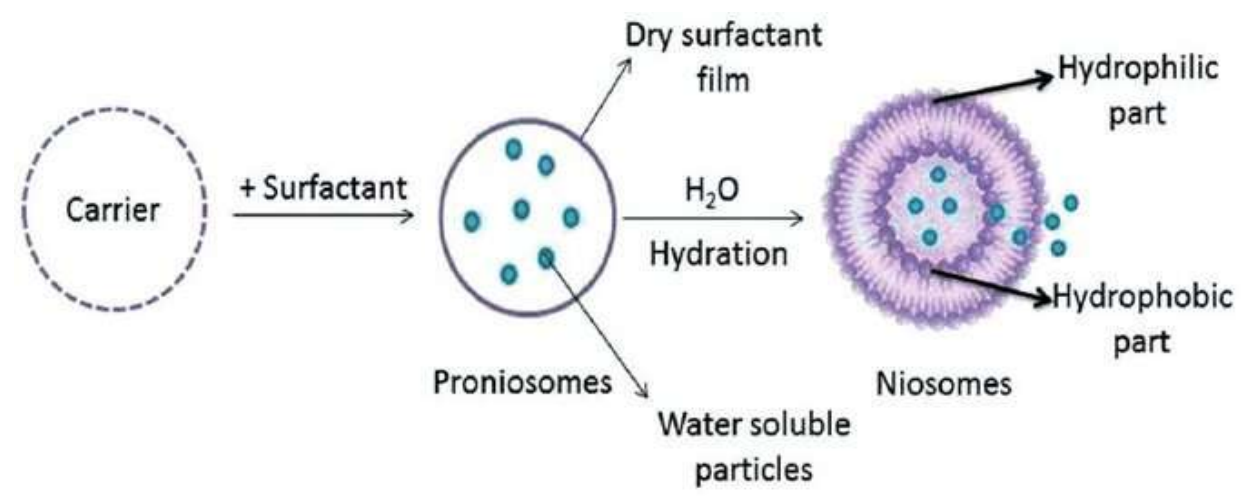

Figure 6: Conversion of Proniosomesto Niosomes

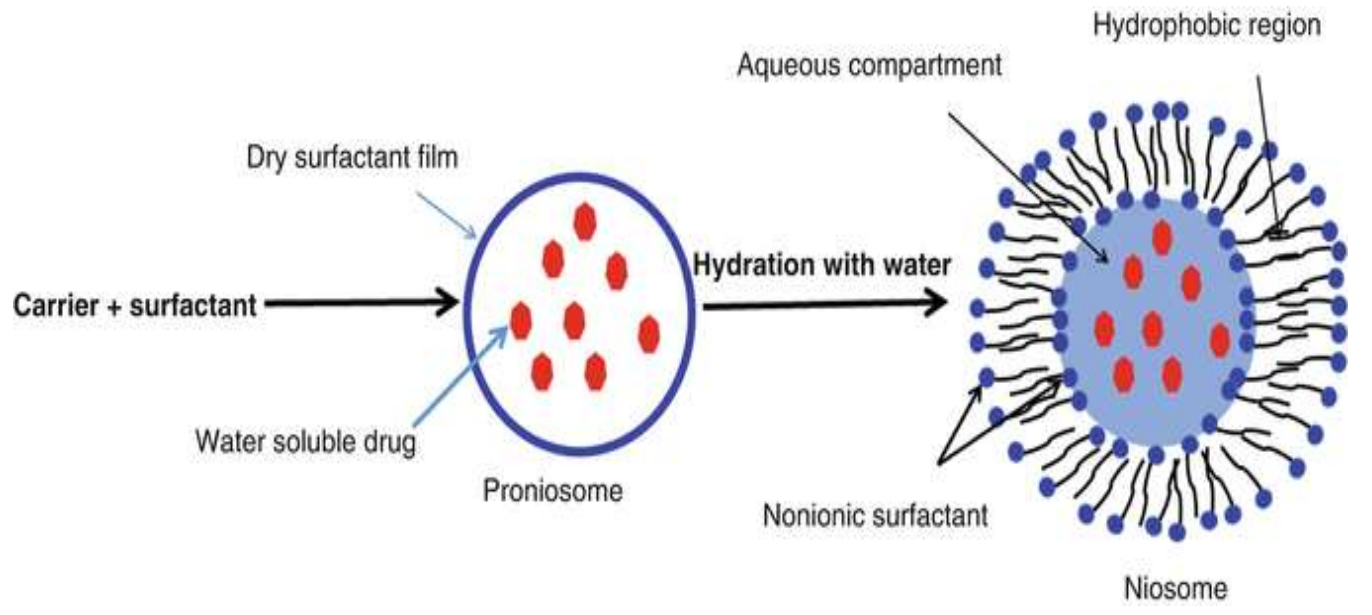

Figure 7: Conversion of Proniosomes

Material used and their action in the proniosomal preparation-

Table 1: [25]

\begin{tabular}{|c|c|c|}
\hline Components & Category & Action \\
\hline Span and Tween & Surfactants & Maintenance of HLB level \\
\hline $\begin{array}{l}\text { Methanol, ether, } \\
\text { chloroform and ethanol }\end{array}$ & Organic solvents & $\begin{array}{l}\text { Influence on vesicle size and } \\
\text { permeability of drug }\end{array}$ \\
\hline Cholesterol and lecithin & $\begin{array}{l}\text { Membrane } \\
\text { stabilizers }\end{array}$ & $\begin{array}{l}\text { Cholesterol influence the stability } \\
\text { and permeability of vesicles. } \\
\text { Lecithin-penetration enhancer. }\end{array}$ \\
\hline $\begin{array}{l}\text { Maltodextrin, lactose, } \\
\text { sorbitol, mannitol }\end{array}$ & Carriers & Holds the drug \\
\hline
\end{tabular}

Table 2: Parameters for characterization and used instruments

\begin{tabular}{lll}
\hline S No. & Parameters & Instruments used \\
\hline 1. & Visualization & Malvern Mastersizer [23] \\
& Vesicle size & Laser diffraction particle size analyzer[13,12] \\
& Size Distribution & Coulter submicron size analyzer[24] \\
& & Optical microscopy[25] \\
2. & Morphological characterization & Optical microscopy[25] \\
& Surface & Transmission electron microscopy[23] \\
& Shape & Scanning electron microscopy[11] \\
3. & Angle of repose & Funnel method[13, 26] \\
\hline
\end{tabular}




\begin{tabular}{|c|c|c|}
\hline 4. & Rate of hydration & Using Neubaur's chamber[2] \\
\hline 5. & Drug content & Modified HPLC method[2] \\
\hline 6. & Aerodynamic behavior & Twin-stage impinger[23] \\
\hline \multirow[t]{2}{*}{7.} & Entrapment efficiency & $\begin{array}{l}\text { Vesicle lysis using alcohol and propylene } \\
\text { glycol[9] }\end{array}$ \\
\hline & & Dialysis method[23] \\
\hline 8. & $\begin{array}{l}\text { Determination of } \\
\text { properties }\end{array}$ & Zeta potential analysis[2] \\
\hline \multirow[t]{4}{*}{9.} & Penetration and permeation Studies & Franz diffusion cells[24] \\
\hline & & Cellophane dialyzing membrane[11] \\
\hline & & USP dissolution apparatus-I[25] \\
\hline & & In vitro skin permeation studies[2, 24] \\
\hline
\end{tabular}

\section{CHARACTERIZATION OF PRONIOSOMES}

\section{Measurement of angle of repose :}

The angle of repose can be measured by two methods.

Funnel Method - Funnel is fixed at height of $2 \mathrm{~cm}$ above the level of the surface. The proniosomal powder was poured into the funnel and passed down through the funnel outlet orifice of $12 \mathrm{~cm}$ to from a cone on the surface. Then the angle of repose was calculated by measuring the height $(\mathrm{h})$ of the cone and the diameter (r/2)) of the base[21].

Cylinder Method -Similar to the funnel method, the proniosomal powder was poured into the cylinder containing outlet orifice which is fixed at a position above the level of surface. The powder flows down through outlet orifice to from a cone. The angle of repose was further calculated by measuring the height $(\mathrm{h})$ of the cone and the diameter $(\mathrm{r} / 2)$ of the base[21].

Angle of repose $(\square)=\operatorname{Tan}^{-1}(\mathrm{~h} / \mathrm{r})$

\section{Scanning electron microscopy (SEM) :}

Particle size of the proniosomes has primary importance. The surface morphology (i.e., roundness, smoothness, and formation of aggregates) and size distribution of proniosomes was studied by SEM. The proniosomal powder was sprinkled and spreader on a double-sided tape that was affixed on an aluminium stubs and then placed in a vacuum chamber of SEM (XL 30 ESEM with EDAX, Philips, Netherlands). The morphological characterization of the samples was observed by using a gaseous secondary electron detector (Working pressure of 0.8 torr, acceleration volage-30kv)[21].

\section{Optical microscopy:}

The niosomes were mounted on a glass slide and observed under a optical microscope (Medilux - 207 RII, Kyowa- E1 etner, Ambala, India). The microscope with magnification of X 1200 used for the morphological observation. The photomicrograph of the preparation was obtained from the microscope by using digital single lens reflex (SLR) camera [21]. 


\section{Measurement of vesicle size :}

Niosomal dispersions are diluted about 100 times in the same medium used for their preparation.

The sample was stirred well before determining the vesicle size. Vesicle size was measured by using Laser diffraction particle size Analyzer, Sympatec, Germany. The apparatus contains HeNe laser beam of $632.8 \mathrm{~nm}$ focused with a minimum power of $5 \mathrm{~mW}$ using a Fourier lens (R-5) to a point at the center of multielement detector and a small volume sample holding cell ( $\mathrm{S}_{\mathrm{u}}$ cell). The average particle size of proniosome derived niosomes was approximately $6 \times 10^{-6} \mathrm{~m}$ while the conventional niosomes contain about $14 \times 10^{-6} \mathrm{~m}[21]$.

\section{Entrapment efficiency :}

Separation of unentrapped drug can be done by various techniques $[2,12]$.

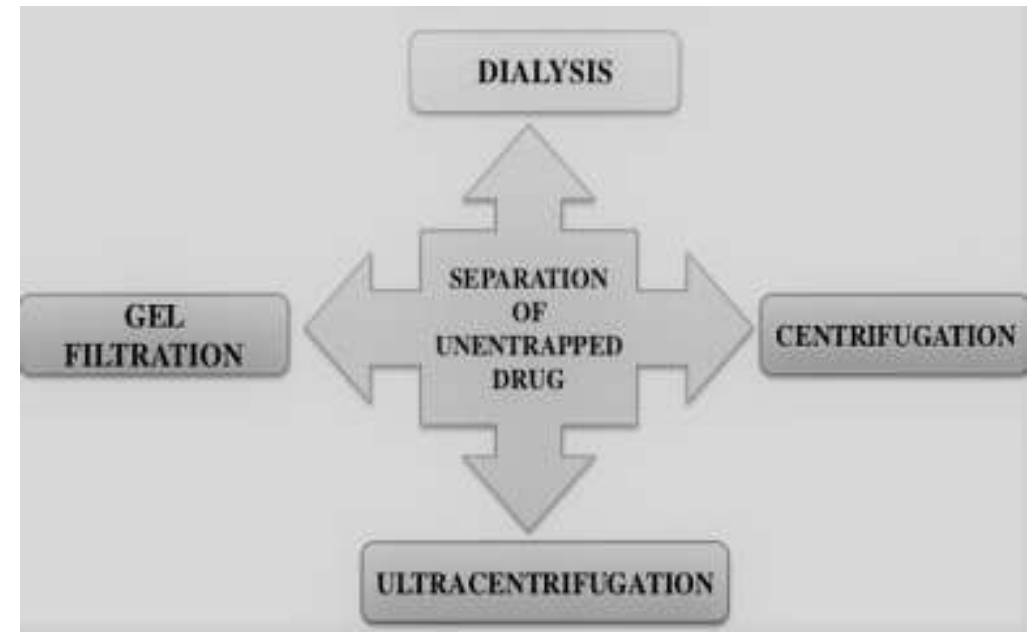

Figure 8:Seperation of unentrapped drug

Dialysis - The niosomal dispersion is dialyzed in dialysis tubing against the suitable dissolution medium at room temperature. The samples are withdrawn at regular time intervals, centrifuged and analyzed for drug content.

Centrifugation- Theproniosomes derived niosomal suspension is centrifuged and supernatant is separated. The resultant pellet is washed and resuspended for obtaining the unentrapped drug free vesicles.

Gel Filtration - The free drug is separated by gel filtration from the niosomal dispersion through a sephadex G-50 column and eluted with suitable mobile phase and analyzed.

Separation of entrapped drug can be done by complete vesicle disruption using 50\% n-propanol (or) $0.1 \%$ Triton X-100 and analyzing the resultant solution by appropriate method.

$$
\text { Percent Drug entrapment }=\frac{\text { Total drug }- \text { Diffused drug }}{\text { Total drug }} \times 100
$$

\section{In vitro Drug Release :}


Proniosomal drug release was determined by using distinct techniques such as Franz cell diffusion, dialysis, reverse dialysis, USP dissolution apparatus Type-1 and molecular porous membrane tubing. Drug release from the suspension can follow any of the mechanism such as desorption from the surface of vesicles (or) diffusion of drug from Bilayered membrane (or) both desorption and diffusion mechanism [2, 11, 22].

\section{Rate of Hydration:}

Spontaneity of niosomal formation is determined by the no. of niosomes formed after hydration of proniosomes for about 15 mins. Proniosomes are taken in a small stoppered glass tube and spread uniformly. $1 \mathrm{ml}$ of saline $(0.154 \mathrm{M} \mathrm{Nacl})$ was added and kept aside without shaking. After 15 - 20min, Small amount was withdrawn and placed on Neubaur's chamber. The no. of niosomes formed from proniosomes was counted [18].

\section{STABILITY STUDIES:}

To determine the stability of proniosomes, the prepared proniosomes are stored at various temperature conditions like refrigeration temperature (i.e., $\left.2-8^{\circ} \mathrm{C}\right)$, room temperature $(25 \pm$ $\left.0.5^{\circ} \mathrm{C}\right)$ and elevated temperature $\left(45 \pm 0.5^{\circ} \mathrm{C}\right)$ for a period of $1-3$ months. Drug content and difference in the average vesicle diameter was monitored periodically.

As per ICH guidelines stability studies for dry proniosomes powders which are meant for reconstitution should be studied for accelerated stability at $40^{\circ} \mathrm{C} / 75 \% \mathrm{RH}$ as per international climatic zones and climatic conditions. After storing for particular period, the product should be evaluated for appearance, color, assay, $\mathrm{pH}$, particulate matter, sterility, preservative content and pyrogenicity $[2,23,25]$.

\section{APPLICATIONS OF PRONIOSOMES}

\section{Proniosomes as drug carriers :}

Proniosomes act as Drug carriers for above mentioned drugs, which are only few examples. Drug delivery has been studied by different methods of administration which includes $1 \mathrm{~V}$, peroral, transdermal, aerosoles and intramuscular. In vivo behavior of proniosomes will be similar to liposomes[27].

\section{Clinical applications:}

In cardiology - Proniosomes as carriers for captopril drug for treatment of hypertension in the form of transdermal delivery which results in an extended release of the drug in the body. Encapsulation of drug is carried out using sorbitan esters, cholesterol and lecithin [21].

In diabetes- Furosemide proniosomes are injected transderrmally which reduces the glucose levels[21]. 
Hormonal therapy - Levonorgestrel proniosomes was given in transdermal drug delivery system. Bioassay for progestational activity was performed including endometrial assay and blockage of development of corpora lutea [21].

Immune response - Niosomes and proniosomes are being used to study the nature of the immune response due to their immunological selectivity, low toxicity and greater stability [21].

Peptide drugs- Oral peptide drug delivery has a limitation of bypassing the enzymes, which leads to breakdown of peptide and protein bonds [21].

Anti-neoplastic Treatment - Niosomes have the ability to alter the metabolism, prolong circulation and half-life of the drug leading to minimal side effects. Doxorubicin and methotrexate niosomes shows an advantageous effects over the unentrapped drugs in decreasing the rate of proliferation of the tumor [21].

Table 3: List of Drugs used in different proniosomal formulations

\begin{tabular}{lll}
\hline Category & Drug & Application \\
\hline NSAID & $\begin{array}{l}\text { Indomethacin } \\
\text { Piroxicam, ketorolac, }\end{array}$ & Oral [21] \\
& $\begin{array}{l}\text { Flurbiprofen, Aceclofenac } \\
\text { Doxorubicin }\end{array}$ & \\
Anticancer & Exemestane & IV [27] 27] \\
& Furasemide & Oral [27] \\
Diuretic & Losartan Potassium, Valsartan, Gel \& Patch [21, 27] \\
Anti-hypertensive & Captopril, Alprenolol HCL & \\
& Cromolyn Sodium & Nebulisable[21] \\
Anti-asthmatic & Chlorpheniramine Maleate & Gel \& Patch [21] \\
Anti-histamatic & Hexadecyl Triglycerol Ether & IV [21] \\
Anti-infectives & Gadolinium & IV [21] \\
Diagnostic imaging & & \\
agents & & \\
\hline
\end{tabular}

\section{CONCLUSION:}

Proniosomes represent a promising drug delivery technologies and represent the structure similar to the liposomes. Hence, they can represent an alternative vesicular systems. Proniosomes derived niosomes are known to avoid many problems such as physical stability problems like aggregation, fusion and leakage. They also provide an additional benefits of transportation, distribution, storage and dosing. From the above article, it is concluded that the concept of entrapment or incorporating the drug into proniosomes for the better targeting of the appropriate tissue target is widely accepted by researchers and academicians.

\section{REFERENCES}

1. Charcosset C, Pham TT, Jaafar-Maalej C, Fessi H. Liposome and niosome preparation using a membrane contactor for scale-up. ColloidsSurf B 2012; 94: 15-21. 
2. Vora B, Khopade AJ, Jain NK. Proniosomes based transdermal delivery of levonorgesterel for effective contraception. J Control Release 1998; 54: 149-165.

3. Raju J, Karthik YJ, Ashok V, Sunkavalli S, Bandari S,Kandadi P, et al. Bioavailability enhancement of zaleplon via proliposomes: Role of surface charge. Eur J Pharm Bio pharm 2012; 80: 347-357.

4. Payne NI, Browning I, Hynes CA. Characterization of proliposomes. J Pharm Sci 1986; 75: 330-333.

5. Katare OP, Vyas SP, Dixit VK. Effervescent granule based proliposomes of ibuprofen. J Microencapsul 1990; 7: 455-462.

6. Baillie AJ, Florence AT, Hume LR, et al. Preparation and properties of niosomesnonionic surfactant vesicles. J Pharm Pharmacol 1985; 37: 863-868.

7. Schreier H, Bouwstra J. Liposomes and niosomes as topical drug carriers-dermal and transdermal drug delivery. J Cont Rel 1994; 30: 1-15.

8. Uchegbu IF, Florence AT. Non-ionic surfactant vesicles (niosomes): physical and pharmaceutical chemistry. Adv Coll Int Sci 1995; 58: 1-55.

9. Uchegbu IF, Vyas SP. Non-ionic surfactant based vesicles (niosomes) in drug delivery. Int J Pharm 1998; 172: 33-70.

10. Carafa M, Santucci E, Lucania G. Lidocaine loaded non-ionic surfactant vesicles: characterization and in-vitro permeation studies. Int J Pharm 2002; 231: 21-32.

11. Alsarra IA, Bosela AA, Ahmed SM, et al. Proniosomes as a drug carrier for transdermal delivery of ketorolac. Eur J Pharm Biopharm 2005; 59: 485-490.

12. Solanki AB, Parikh JR, Parikh RH. Formulation and optimization of piroxicamproniosomes by 3-factor, 3-level box-behnken design. AAPS Pharm Sci Tech 2007; 8: $1-7$.

13. Hu C, Rhodes DG. Proniosomes: a novel drug carrier preparation. Int J Pharm 1999; 185 : 23-35.

14. Mahmoud Mokhtar, Omaima A. Sammour, Mohammed A. Hammad, et al. Effect of some formulation parameters on flurbiprofen encapsulation and release rates of niosomes prepared from proniosomes. Int J Pharm 2008; 361: 104-111.

15. Walve JR, Rane BR, Guajarati NA. Proniosomes: A surrogate carrier for improved transdermal drug delivery system. IJRAP 2011; 2: 743-750.

16. Blazek-Welsh AI, Rhodes DG. Maltodextrin-based proniosomes. AAPS Pharm Sci Tech 2001a; 3: 1-8. 
17. Malhotra M, Jain NK. Niosomes as drug carriers. Indian Drugs 1994; 31: 81-86.

18. Kapil Kumar, Awadhesh Kumar Rai. Development and Evaluation of Proniosomes as a promising drug carrier to improve Transdermal drug delivery. Int. Res. J. Pharm 2011; 2(11): 71-74.

19. Ammara HO, Ghorabb M, El-Nahhasc SA, et al. Proniosomes as a carrier system for transdermal delivery of tenoxicam. Int J Pharm 2011; 405: 142-152.

20. Perrett S, Golding M, Williams WP. A simple method for the preparation of liposomes for pharmaceutical applications: characterization of the liposomes. J Pharm Pharmacol 1991; 43: 154-161.

21. G.V. Radha, T. Sudha Rani, B. Sarvani. A review on proniosomal drug delivery system for targeted drug action. JBCP 2013; 4-2: 42-48.

22. Vyas SP, Khar RK. Targeted and controlled drug delivery: novel carrier systems. New Delhi, India: CBS Publications 2002.

23. Abd-Elbary A, El-laithy MI, Tadros HM. Sucrose stearate-based proniosome-derived niosomes for the nebulisable delivery of cromolyn sodium. Int J Pharm 2008; 357: 189198.

24. Fang JY, Yu SY, Wu PC, et al. In-vitro skin permeation of estradiol from various proniosome formulations. Int J Pharm 2001; 215: 91-99.

25. Ankur Gupta, Sunil Prajapati, M Balamurugan, Mamta Singh, et al. Design and development of a proniosomal transdermal drug delivery system for captopril. Trop J Pharm Res 2007; 6: 687-693.

26. Lieberman H, Lachman L, Schwartz J. Pharmaceutical dosage forms: tablets, Vol. 2, 2nd ed. New York;1990.

27. Venkata Ramesh Yasam, Satya LavanyaJakki, Jawahar Natarajan et al. A review on Novel vesicular drug delivery: Proniosomes. Drug delivery 2013; Early Online: 1-7.

28. Adnan A, Nilu J, Zeenat I, et al. Feasibility of proniosomes based transdermal delivery of frusemide: formulation optimization and pharmacotechnical evaluation. Pharm Dev Technol 2008; 13: 155-163.

29. Ajay S, Jolly P, Rajesh P. Preparation, characterization, optimization, and stability studies of Aceclofenac Proniosomes. Iran J Pharm Res 2008; 7: 237-246.

30. Azmin MN, Florence AT, Handjani-Vila RM, et al. The effect of non-ionic surfactant vesicle (niosome) entrapment on the absorption and distribution of methotrexate in mice. J Pharm Pharmacol 1985; 37: 237-242. 
31. Bangham AD, Standish MM, Watkins JC. Diffusion of univalent ions across the lamellae of swollen phospholipids. J Mol Biol 1965; 13: 238-252.

32. Biju SS, Talegaonkar S, Misra PR, et al. Vesicular systems: an overview. Indian J Pharm Sci 2006; 68: 141-153.

33. Blazek-Welsh AI, Rhodes DG. SEM imaging predicts quality of niosomes from maltodextrin-based proniosomes. Pharmaceut Res 2001b; 18: 656-661.

34. Brinon L, Geiger S, Alard V, et al. Peercutaneous absorption of sunscreen from liquid crystalline phases. J Control Release 1999; 60: 67-76.

35. Chandraprakash KS, Udupa N, Umadevi $P$, et al. Pharmacokinetic evaluation of surfactant vesicles containing methotrexate in tumor bearing mice. Int J Pharm 1990; 61:R1-3.

36. Chauhan S, Luorence MJ. The preparation of polyoxyethylene containing non-ionic surfactant vesicles. J Pharm Pharmacol 1989; 41: 6-11.

37. Cioca G, James HA, Manuel LT, et al. Liquid crystal containing cosmetic US 4,999,348 issued 12 Mar 1991.

38. Devaraj GN, Parakh SR, Devraj R, et al. Release studies on Niosomes containing fatty alcohols as bilayer stabilizers instead of cholesterol. J Coll Int Sci 1991; 251: 360-365.

39. El-Laithy HM, Shoukry O, Mahran LG. Novel sugar esters proniosomes for transdermal delivery of vinpocetine: preclinical and clinical studies. Eur J Pharm Biopharm 2011; 77: $43-55$.

40. Gayatri DS, Venkatesh P, Udupa N. Niosomal sumatriptan succinate for nasal administration. Int J Pharm Sci 2000; 62: 479-481.

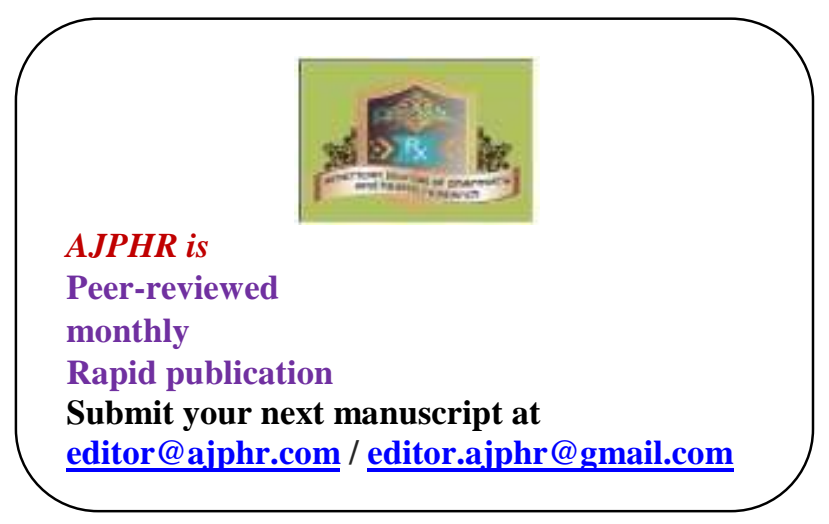

